\title{
PENGARUH PENAMBAHAN STASIUN-STASIUN SEISMIK (STPI, TSPI, DAN IWPI) TERHADAP ANALISA PENENTUAN PARAMETER GEMPA BUMI STUDI KASUS GEMPA BUMI DI WILAYAH PAPUA BARAT TAHUN 2019 - 2020.
}

\author{
Andri wijaya bidang \\ Stasiun geofisika kelas III Sorong, BMKG \\ Email: andri.wijaya@bmkg.go.id
}

\begin{abstract}
Abstrak
Wilayah Provinsi Papua Barat yang luas dan rawan aktifitas kegempaan membutuhkan stasiun seismik untuk menentukan lokasi gempabumi, oleh karena itu bagaimana dampak yang ditimbulkan akibat penambahan stasiun sesmik terhadap analisa penentuan parameter gempabumi dan kegempaan wilayah Provinsi Papua Barat?. Data yang digunakan adalah data hasil analisa gempa di stasiun-stasiun seismik yang lama (SIJI,SWI,MWPI,RKPI,FAKI dan RAPI) dan stasiun seismik baru (STPI, TSPI, dan IWPI) menggunakan perangkat lunak Seiscomp3: studi kasus gempa tanggal 19 Maret 2020, 24 April 2020, 26 April 2020, 27 April 2020 dan 28 April 2020 serta menggunakan data kegempaan periode Juni 2019 hingga Januari 2020 (sebelum terpasang stasiun-stasiun seimik baru) dan data kegempaan periode Februari 2020 hingga Mei 2020 (Setelah terpasang stasiun-stasiun seimik yang baru). Data-data tersebut kemudian diolah dengan metode kuantitatif dengan membandingkan data hasil analisa sebelum dan sesudah menggunakan stasiun seimik baru. Dari hasil penelitian dapat ditarik kesimpulan dengan adanya penambahan stasiun-stasiun seismik baru berpengaruh pada lokasi episenter dengan melihat nilai dari faktor RMS Error, Azimuth gap, Error lintang dan bujur, bertambahnya frekuensi kegempaan, dan munculnya kelompok gempa baru di wilayah Provinsi Papua Barat. Saran yang dapat diperhatihan adalah perlunya menambah lebih banyak stasiun-stasiun seismik baru sehingga tidak timbul azimuth gap yang lebih dari $180^{\circ}$ yang dapat mempengaruhi tingkat akurasi lokasi episenter gempa dan perlunya studi lanjutan terkait penelitian ini.
\end{abstract}

Kata kunci: Gempa bumi, azimuth gap, RMS Error, seismometer, stasiun seismic.

\begin{abstract}
Province of West Papua has large territory and active tectonics. It requires seismic stations to determine the location of the earthquake, it important to recognize the effects of adding seismic stations on proccessing earthquake parameters and the seismic pattern of the region of West Papua Province. Using earthquake analysis data from earlier seismic stations (SIJI, SWI, MWPI, RKPI, FAKI and RAPI) and recent seismic stations (STPI, TSPI, and IWPI). This study used Seiscomp3 software to determine earthquake parameters and GMT (Generic Mapping Tool) version 5 to plot epicenter. The datas are earthquake events at 19th March 2020, 24th April 2020, 26th April 2020, 27th April 2020, 28th April 2020, the epicenter of earthquake events from the period June 2019 to January 2020 (before the recent seismic stations was installed) and from the period February 2020 to May 2020 period (the recent seismic stations was installed). Then we applied quantitative methods and comparing the data. The results are: the recently seismic stations can effect the analyze of earthquake parameters by looking at the value of the RMS Error factor, Azimuth gap, latitude error and longitude error, this study found increasing earthquake events and new cluster eartquakes after added recent seismic stations. We should install more new seismic stations to get accuracy of earthquake parameters and we need related advanced studies.
\end{abstract}

Keywords: Earthquake, azimuth gap, RMS Error, seismometer, seismic station

\section{Pendahuluan}

Kondisi tektonik wilayah Provinsi Papua Barat dipengaruhi oleh pertemuan empat lempeng tektonik dunia yaitu lempeng tektonik Lempeng Pasifik, Eurasia, Australia dan Filipina. Adanya tekanan dan regangan dari pertemuan lempeng-lempeng ini sehingga menyebabkan terbentuknya daerah subduksi dan sesar-sesar lokal. Daerah-daerah ini merupakan sumber terjadinya gempabumi yang dapat berdampak pada permukaan bumi dan aktifitas manusia (Ibrahim.,dkk. 2010 dan Kearey.,dkk.1992)

Penentuan parameter gempabumi memerlukan peralatan seismometer yaitu dengan menganalisa gelombang gempa yang terekam oleh seismometerseismometer yang terpasang menyebar disekitar wilayah Provinsi papua Barat. Pada tahun 2018, Badan Meteorologi Klimatologi dan Geofisika (BMKG) telah memasang 7 (tujuh) unit seismometer untuk mendeteksi gempabumi yaitu stasiun seismik RAPI berada di Waisai Raja Ampat, SIJI dan SWI berada di kota Sorong, MWPI berada di kota Manokwari, RKPI berada di kota Ransiki, FAKI berada di kota Fak-fak, KMPI berada di kota Kaimana, dan tahun 2020 bertambah 3 (empat) unit seismometer yaitu STPI berada di kota Sausapor, TSPI berada di kota Teminabuan, dan IWPI berada di kota Wasior sehingga jumlah keseluruhan stasiun seismik BMKG di provinsi Papua Barat menjadi 10 unit seismometer (Lihat Gambar.1 dan Tabel.1), jenis seismometer-seismometer tersebut adalah BroadBand 
(Sample rate $\geq 10$ hingga $<80$ ). Seismometerseismometer ini akan mengirimkan sinyal hasil rekaman gelombang atau getaran tanah secara realtime kemudian dianalisa oleh pengamat.

Penentuan lokasi gempa bumi memerlukan data waktu penjalaran gelombang $\mathrm{P}$ sekurangkurangnya tiga stasiun seismik atau seismometer. Setiap stasiun seismik akan menghasilkan jarak episenter yang digambarkan dalam lingkaran. Data dari tiga stasiun seismik menghilangkan keraguan karena terdapat titik pertemuan dari tiga lingkaran tersebut yaitu episenter (Lowrie, 1997), dengan menggunakan lebih banyak stasiun seismik maka hasil analisa gempa akan lebih baik (Santoso, 2002).

Batasan masalah penelitian ini adalah model kecepatan lapisan dianggap homogen isotropis, faktor pengaruh respon instrumen diabaikan, dan hanya menggunakan waktu tiba fase gelombang $\mathrm{P}$ dalam penentuan parameter. Dalam penelitian ini juga memakai model kecepatan 1-D IASPEI91. Permasalahan yang akan dihadapi adalah bagaimana dampak yang ditimbulkan akibat penambahan stasiun sesmik terhadap analisa penentuan parameter gempabumi? dan bagaimana kelompok kegempaan wilayah Provinsi Papua Barat? Penulis membandingkan hasil analisa parameter gempa bumi dari sebelum dan sesudah menggunakan stasiun seimik yang baru, menghitung jumlah trend kegempaan dan menentukan pola episenter gempa pada saat sebelum dan sesudah terpasang tiga stasiun seismik. Sehingga penelitian ini bertujuan agar dapat menjelaskan pengaruh akibat penambahan stasiun seismik STPI, TSPI, dan IWPI terhadap analisa penentuan parameter gempabumi di wilayah Provinsi Papua Barat.

\section{Metode Penelitian}

Data yang digunakan dalam penelitian ini adalah seismogram digital dari stasiun seismik RAPI, SWI, SIJI, STPI, TSPI, IWPI, RKPI dan FAKI, data parameter gempabumi tanggal 19 Maret 2020, 24 April 2020, 26 April 2020, 27 April 2020 dan 28 April 2020, dan data episenter gempabumi pada bulan Juni 2019 hingga Bulan Januari 2020 merupakan data gempa dari stasiun-stasiun seimik yang lama (SIJI, SWI, RKPI, MWPI, RAPI, FAKI dan KMPI) sedangkan pada bulan Februari 2020 hingga bulan Mei 2020 merupakan data gempa dari stasiun-stasiun lama yang ditambah dengan stasiun-stasiun baru (STPI, TSPI, dan IWPI) di Provinsi Papua Barat (Gambar 17)

Metode yang dilakukan Metode kuantitatif dengan membandingkan hasil analisa gempa sebelum dan sesudah menggunakan tiga stasiun seismik baru (STPI, TPSI dan IWPI). Penelitian ini juga menggunakan perangkat lunak analisa gempabumi yang digunakan oleh BMKG yaitu Seiscomp3 sebagai data yang dibandingkan.

Pengolahan data gelombang seismik gempa menggunakan perangkat lunak Seiscomp3, dalam tahap analisa digunakan teknik filter bandpass untuk menghilangkan frekuensi gelombang nois pada sampel gelombang gempa agar mempermudah dalam menganalisis waktu tiba fase gelombang P. Setelah itu, proses penentuan fase gelombang $\mathrm{P}$ pada sampel gelombang gempa dilakukan secara manual berdasarkan pengamat dan kemudian perhitungan hasil parameter diproses secara otomatis oleh sofware Seiscomp3. Pada penelitian ini analisa picking gelombang gempa pada Seiscomp3 hanya melakukan picking fase gelombang $\mathrm{P}$ karena memiliki tingkat akurasi yang tinggi dalam menentukan lokasi gempa. Penentuan fase waktu tiba gelombang $\mathrm{S}$ lebih rumit karena makin besar Signal-to-Noise Rasio dan menambah ketidakpastian (Husen dan Hardebeck, 2010).

Data parameter gempabumi kemudian dikumpulkan dan diinput menjadi grafik batang berdasarkan frekuensi vs magnitudo dan kemudian dilakukan kajian secara deskripsi pola tren dari data gempabumi tersebut.

Analisa paremeter gempabumi memerlukan hasil analisa parameter gempa sebelum dan sesudah penambahan stasiun seimik. Kemudian dilakukan perbandingan hasilnya.

Hasil pengamatan analisa gempabumi berupa koordinat episenter gempabumi juga dipetakan dengan menggunakan Generic Mapping Tools (GMT) versi 5 kemudian menentukan pola sebaran baru episenter gempa akibat adanya stasiun seismik yang baru terpasang.

\section{Pembahasan}

\section{Nilai RMS Error Residual}

Hasil analisa menunjukkan adanya nilai RMS (Root mean Square) Error residual (Lihat Tabel) yang berbeda pada setiap kejadian gempa dan jumlah stasiun seismik yang digunakan. Semakin sedikit penggunaan stasiun seismik dalam pengamatan, semakin rendah nilai RMSnya. Sebaliknya semakin banyak data stasiun seismik yang dipakai untuk pengamatan, maka semakin sulit mencapai nilai RMS yang mendekati nol. Standarisasi pengamatan dan prakiraan menggunakan inputan RMS Error mempunyai hubungan dengan koefisien korelasi. Contohnya, Jika koefisien korelasinya bernilai 1 , maka RMS Error nya bernilai 0, karena semua titik berada pada garis regresi (artinya tidak ada error). Nilai RMS errornya bergantung kepada model kecepatan yang digunakan pada sofware analisa menentukan lokasi gempa, kualitas penetuan waktu tiba gelombang, dan prosedur yang digunakan (Husen dkk, 2003).

Studi kasus gempabumi 19 Maret, 24 April, 26 April, 27 April, dan 28 April 2020, kita dapat melihat pada Tabel. 2 hingga Tabel. 6 dan Gambar 13 menjelaskan bahwa perbandingan Nilai RMS error residu sebelum dan sesudah menggunakan stasiun seismik baru (STPI,TSPI, IWPI)

Tanggal 24 April dan 27 April 2020 terjadi kenaikan nilai RMS error residu setelah ditambahkan 
stasiun seismik (STPI dan TSPI) dan pada tanggal 28 April tidak mengalami perubahan.

Tanggal 19 Maret 2020, nilai RMS error residu sebelum menggunakan stasiun seismik baru mengalami error disebabkan data yang diterima hanya dua stasiun seismik yang lama (MWPI dan RKPI), sedangkan perangkat lunak Seiscomp3 hanya mampu menganalisa minimum tiga stasiun seismik. Hal yang berbeda ketika dimasukkan stasiun seismik IWPI dalam analisa kemudian mampu menghasilkan parameter gempa dan RMS Error residu. Demikian pula hal yang sama terjadi pada gempa tanggal 26 April 2020 hanya terdapat dua stasiun seismik (SIJI dan SWI), setelah menggunakan tambahan stasiun seismik baru (STPI), dapat dilakukan proses analisa parameter gempabumi.

\section{Nilai Azimuth gap}

Semakin besar azimuth gap maka semakin besar pula kesalahan penentuan lokasi gempabumi. (Belinić dan Snježana, 2017). Cakupan azimuth antar stasiun seismik memiliki pengaruh yang kuat dalam akurasi titik gempabumi. Azimuth gap adalah sudut terbesar yang memisahkan dua stasiun seimik yang dihitung dari satu kejadian episenter gempabumi. Jika azimuth gap lebih dari $180^{\circ}$, tingkat akurasi lokasi episenternya menjadi rendah (Tiira,Timo, dkk.,2015).

Azimuth gap merupakan salah satu parameter yang dipakai untuk mendapat indikasi keakurasian episenter gempabumi. Azimuth gap yang sama atau melebihi sudut $180^{\circ}$ mengidikasi bahwa stasiunstasiun seismik berada hanya pada satu sisi bagian kejadian gempabumi (Havskov and Ottemöller,2010). Untuk mendapatkan azimuth gap yang baik untuk satu kejadian gempa maka harus memperhatikan distribusi merata antara stasiun-stasiun seimik yang mengelilingi episenter gempa (Bondár and McLaughlin 2009).

Studi kasus gempabumi 24 April dan 28 April 2020, nilai perbandingan Azimuth gap terjadi penurunan setelah menggunakan stasiun seimik baru (STPI dan TSPI). Terdapat tiga kejadian gempa yaitu tanggal 24, 26, dan 28 April 2020 memiliki azimuth gap dibawah $165^{\circ}$ Sedangkan pada tanggal 19 Maret dan 27 April 2020 perbandingan nilai Azimuth gap masih bernilai lebih dari $180^{\circ}$ dikarenakan sebaran stasiun seismik hanya berada pada salah satu sisi saja dan tidak tersebar mengelilingi episenter gempa.

\section{Error lintang bujur episenter}

Gempabumi tanggal 24 April, 27 April dan 28 April 2020 memiliki trend error lintang dan bujur yang menurun (lihat Gambar 15 dan 16) setelah ditambahkan stasiun seismik baru (STPI dan TSPI).

Pada Gambar 9 dan 10 terlihat bahwa koordinat episenter gempa tanggal 27 April 2020 mengalami perubahan pergeseran lokasi gempa yang signifikan sebelum ditambahkan stasiun seimik baru (STPI dan TSPI), posisi episenter gempa berada di bagian selatan stasiun-stasiun seismik dan kemudian setelah ditambahkan stasiun seismik STPI dan TSPI dalam proses analisa, posisi episenter gempa menjadi bergeser kearah bagian utara stasiun-stasiun seismik. Sedangkan pada gempa tanggal 19 Maret dan 26 April 2020, hanya terdapat dua stasiun seismik lama yang merekam gempa-gempa tersebut sehingga tidak memungkinkan untuk dapat dianalisa dan untuk itu diperlukan tambahan analisa dari stasiun seimik baru seperti STPI, TSPI dan IWPI.

\section{Sebaran dan frekuensi episenter gempa.}

Hasil pemetaan dari kejadian gempabumi wilayah Papua Barat dan sekitarnya periode Juni 2019 - Mei 2020 menunjukan adanya kelompok gempa-gempa yang baru terdeteksi. Kelompok gempa ini muncul setelahnya adanya penambahan stasiun seismik baru pada analisa gempabumi BMKG (kelompok ini diperlihatkan pada lingkaran merah pada Gambar 15) terlihat adanya 3 kelompok gempa yang umumnya terjadi di wilayah Kabupaten Tambrauw dan Kabupaten Sorong Selatan. Gambar 2 menjelaskan sebelum penambahan stasiun-stasiun seismik baru yaitu data gempa bulan juni 2019 hingga Januari 2020 mengalami fluktuasi akan tetapi setelah ditambahkan stasiun-stasiun seismik baru (STPI, TSPI dan IWPI) pada periode bulan febuari 2020 hingga Mei 2020 terjadi peningkatan frekuensi kegempaan di wilayah Provinsi Papua Barat.

\section{Kesimpulan}

a. Nilai RMS Error residu setelah ditambahkan stasiun-stasiun seimik baru (STPI, TSPI, dan IWPI) kedalam proses analisa masih berada pada nilai ambang batas wajar yaitu tidak melebihi 1 (satu).

b. Setelah ditambahkan stasiun-stasiun seismik baru (STPI, TSPI, dan IWPI), nilai azimuth gap mengalami perbaikan sudutnya menjadi lebih kecil dari azimuth gap sebelum ditambahkan stasiun-stasiun seismik baru bahkan mencapai $\leq$ $180^{\circ}$. Sehingga tingkat akurasi lokasi episenternya menjadi tinggi.

c. Nilai error lintang dan bujur menjadi turun setelah ditambahkan stasiun-stasiun seismik baru (STPI, TSPI, dan IWPI) berdampak pada mengurangi kesalahan penentuan posisi lokasi gempabumi.

d. Terjadi peningkatan deteksi gempabumi setelah terpasang stasiun-stasiun seismik baru (STPI, TSPI, dan IWPI) (Lihat pada gambar 2)

e. Peta seismisitas kegempaan sebelum dan sesudah penambahan sensor baru menunjukan adanya 3 cluster baru yaitu 2 Cluster berada pada segmen sesar Sorong - Klararea dan 1 cluster berada pada segmen sesar Teminabuan

\section{Daftar pustaka}

Belinić, T., \& Snježana, M. (2017). Empirical criteria for the accuracy of earthquake locations on the Croatian territory. GEOFIZIKA VOL. 34. DOI: 10.15233/gfz.2017.34.5

Bondár, I., \& McLaughlin, K. (2009). Seismic location bias and uncertainty in the presence of correlated and non-Gaussian travel-time errors. 
Bulletin of the Seismological Society of America 99 (1), 172-193

Havskov, J., \& Ottemöller, L. (2010). Routine Data Processing in Earthquake Seismology. Spinger Dordrecht Heidelberg London New York

Husen, S., Kissling, E., Deichmann, N., Wiemer, S., Giardini, D., \& Baer, M. (2003), Probabilistic earthquake location in complex threedimensional velocity models: Application to Switzerland, J.Geophys. Res., 108, doi: 10.1029/2002JB001778.

Husen, S., \& Hardebeck, J. L. (2010). Earthquake location accuracy, Community Online Resource for Statistical Seismicity Analysis, DOI:10.5078/corssa-55815573.

Ibrahim, G., Subardjo., \& Sendjaja, P. (2010). Tektonik dan Mineral di Indonesia. Badan Meteorologi Klimatologi dan Geofisika.
Kearey, P., \& Frederick, J, V. (1992). Global Tectonics. Blackwell Scientific Publications.

Lowrie, W. (1997). Fundamentals of Geophysics. Cambridge University Press (Second Edition).

Santoso, D. (2002). Pengantar Teknik Geofisika. Institut Teknologi Bandung.Bandung

Tiira,T.,Uski, M., Kortstrom, J., Kaisko, O., and Korja, A. (2015). Local seismic network for monitoring of a potential nuclear power plant area. Journal of Seismology volume 20, pages 397-417(2016).

From https://link.springer.com/article/10.1007/s10950015-9534-8 